\title{
Modification and Validation of HPLC Analytical Method for Estimation of Clotrimazole in Health Care Products
}

\author{
Shahnaz Usman ${ }^{1 *}$, Ali Muhammad Zulfiqar ${ }^{2}$, Jenish Shah², Venkat Ramesh ${ }^{1}$ and Sawarkar Sudhir ${ }^{2}$ \\ ${ }^{1}$ Department of Pharmaceutics, RAK College of Pharmaceutical Sciences, RAKMHSU, Ras Al Khaimah, UAE \\ ${ }^{2}$ Dabur International Limited, Ras Al Khaimah, UAE
}

\begin{abstract}
Objective: The aim of the study was to modify the USP analytical method and validate it for the estimation of clotrimazole in health care cream by using reverse phase HPLC.

Methods: LC-20AD liquid chromatography equipped with SPD-20A UV-VIS detector was used for analysis. The separation was done on $\mathrm{C} 18$ column which was attached with loop $20 \mu \mathrm{L}$. Mobile phase was consisting of methanol: $\mathrm{K}_{2} \mathrm{HPO}_{4}(85: 15)$ and flow rate was $1.5 \mathrm{~mL} / \mathrm{min}$. The method was validated as per the $\mathrm{ICH}$ guidelines.

Results: The method is selective and reproducible, capable to separate all possible excipients and help to quantify accurately the amount of clotrimazole in health care product. The percentage coefficient variation (\% CV) of the retention times and the peak areas were $0.504 \%$ and $1.453 \%$, respectively. The linearity was evaluated by least square method i.e., $r^{2}=0.9996$. The limits of detection (LOD) and limits of quantitation (LOQ) for clotrimazole were 0.25 $\mu \mathrm{g} / \mathrm{mL}$ and $0.5 \mu \mathrm{g} / \mathrm{mL}$ respectively. The results of Instrumental precision were $103.5 \%$ with $\% \mathrm{CV}$ of $0.612 \%$ and the intermediate precision was 0.35 to $1.43 \%$. The recoveries at three concentrations levels over a range of $80-120 \%$ were found within the range of 101.2 to $103.8 \%$ as per ICH guidelines. The results of robustness show no major changes occurring over changes in flow rate from $1.4 \mathrm{~mL} / \mathrm{min}$. to $1.6 \mathrm{~mL} / \mathrm{min}$. The method was also applied for the analysis of clotrimazole in formulated health care cream and marketed pharmaceutical creams that contain clotrimazole.
\end{abstract}

Conclusion: It was concluded that the method is so simple, easy and applicable. It could be easily used for the analysis of compound in its dosage form. The robustness and ruggedness of the method are significantly broader, reproducible and could be adjusted according the needs.

Keywords: Clotrimazole; Health care product; Anti-itching cream; HPLC analytical method; Method validation; Antifungal

\section{Introduction}

Clotrimazole is an antifungal medication commonly used in the treatment of fungal infections (of both humans and other animals) such as vaginal yeast infections, oral thrush, and ringworm.

The compound (3) is produced by alkylating imidazole (1) with o-chlorotrityl chloride (2) in acetone, with triethylamine as the base [1] (Figure 1).

Additionally, clotrimazole is used to treat the sickling of cells (related to sickle cell anemia) by blocking ion channels or clocip $\beta$ channels in the red blood cell membrane, keeping ions and water within the cell $[2,3]$.

The primary mechanism of action of clotrimazole is against the division and growing of fungi [4]. Clotrimazole alters the permeability of the fungal cell wall and inhibits the activity of enzymes within the cell [1]. Clotrimazole causes holes to appear in the cell membranes, essential constituents of the fungal cells can leak out. This kills the fungi and treats the infection.

Before using the analytical method for the determination of any compound the adjustment and modification of method is required as per feasibility. Analytical methods must be validated to provide reliable data not only for regulatory submissions but also essential for a number of purposes, including testing for QC release, testing of stability samples, testing of reference materials and to provide data to support the specifications.

High-performance liquid chromatography (HPLC) is a chromatographic method that is used to separate a mixture of compounds in analytical chemistry and biochemistry to identify, quantify or purify the individual components of the mixture $[4,5]$.
The objective of this study was to prepare an anti-itching cream which contains clotrimazole as active ingredient and blend with herbal and non-herbal excipients. Pick USP standard method for the analysis of Clotrimazole and carry out the modification and validation by using various parameters like system suitability, specificity range and linearity, accuracy, precision and robustness in accordance with ICH guidelines. After suitable modification, the method was used for the estimation of Clotrimazole in anti-itching cream.

\section{Materials and Methods}

\section{Instruments}

The HPLC system utilized consists of a LC-20AD liquid chromatography equipped with SPD-20A UV-VIS detector. Chromatographic separations were performed on C18 $(4.6 \times 250 \mathrm{~mm}$, L1; $5 \mu \mathrm{m}$ packing) which was attached with loop $20 \mu \mathrm{L}$ and connected with HPLC-Dell system. In addition, electronic balance, microliter syringe, micropipette and micro-pore filtration assembly were used in this study.

*Corresponding author: Shahnaz Usman, Department of Pharmaceutics, RAK College of Pharmaceutical Sciences, RAKMHSU, Ras Al Khaimah, UAE, Tel: +971558902559; Fax: +97172269997; E-mail: shahnaz.usman@rakmhsu.ac.ae (or) shahnazgauhar@gmail.com

Received December 19, 2016; Accepted December 27, 2016; Published January 03, 2017

Citation: Usman S, Zulfiqar AM, Shah J, Ramesh V, Sudhir S (2017) Modification and Validation of HPLC Analytical Method for Estimation of Clotrimazole in Health Care Products. Nat Prod Chem Res 5: 247. doi: 10.4172/2459-6836.1000247

Copyright: @ 2017 Usman S, et al. This is an open-access article distributed under the terms of the Creative Commons Attribution License, which permits unrestricted use, distribution, and reproduction in any medium, provided the original author and source are credited. 


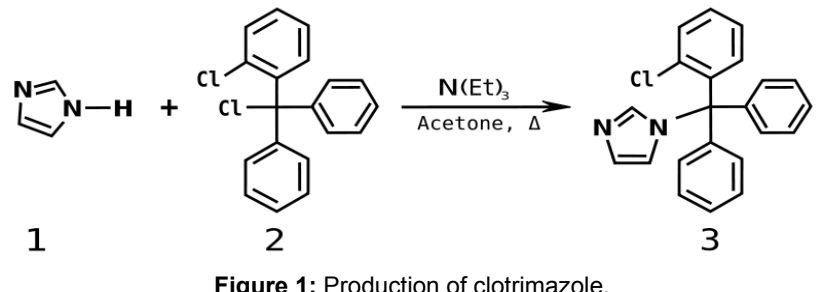

Figure 1: Production of clotrimazole.

\section{Materials}

Clotrimazole (Reference standard) powder, methanol, acetonitrile, dibasic potassium phosphate and double distilled water, all solvents were of HPLC grade and reagents of analytical grade. Clotrimazole anti-itching cream was provided by Dabur international Ras Al Khaimah. While the marketed brands were collected from local market of Ras $\mathrm{Al}$ Khaimah.

\section{Preparation of anti-itching cream}

It consisted of two phases, oil and aqueous. In aqueous phase added oleth. Oil phase contained cetostearyl alcohol, arlacel, ceteareth 20 , petroleum jelly and linseed oil. Temperature was maintained at $75^{\circ} \mathrm{C}$ for both phases separately and oil phase was transferred in to water phase. The mixture was homogenized for 15 minutes. When temperature reached at $45-40^{\circ} \mathrm{C}$ optiphen mint plus and pre blended mixture of clotrimazole, boric acid and zinc oxide (dispersed) in propylene glycol was added. Lastly when temperature reached at $35^{\circ} \mathrm{C}$ the pre-blend having menthol and perfume sweet floral was added and mixed for 1520 minutes to get a clear formulation.

\section{Preparation of mobile phase}

Mobile phase consisted on methanol: $\mathrm{K}_{2} \mathrm{HPO}_{4}(85: 15) . \mathrm{K}_{2} \mathrm{HPO}_{4}$ solutions were filtered through filtration unit (Millipore, $0.45 \mu \mathrm{m}$ pore size) and degassed before use. The flow rate was maintained at $1.5 \mathrm{~mL} /$ min and volume of injection was $20 \mu \mathrm{L}$. Detection was performed at a wavelength of $254 \mathrm{~nm}$ and analysis was carried out at ambient temperature.

\section{Preparation of stock solution}

$50 \mathrm{mg}$ of clotrimazole RS was weighed accurately and transferred to $100 \mathrm{~mL}$ volumetric flask. Diluted with methanol, the concentration of stock solution was $500 \mu \mathrm{g} / \mathrm{mL}$ (on dried basis).

\section{Preparation of sample solution}

Accurately weighed $2.5 \mathrm{~g}$ of clotrimazole herbal health care product (1\%) into a $100 \mathrm{~mL}$ volumetric flask dissolved and diluted to volume with methanol $(250 \mu \mathrm{g} / \mathrm{mL})$.

\section{Method optimization and validation}

The meaning of analytical validation, to the pharmaceutical world, is the process to confirm that an analytical procedure does what it purports to do: that is, to document through laboratory studies that the measurement procedure can reliably assess the identity, strength and quality of a bulk drug substance, excipient or finished pharmaceutical product.

The present experiment was carried-out according to the official specifications of United State Pharmacopeias (USP-36), International Conference on Harmonization (ICH-1996) and Centre of Drug Evaluation and Research (CDER-1994) [6-8]. In the present study analytical method for the estimation of clotrimazole was validated with respect to system suitability, specificity, linearity, limit of detection, limit of quantification, precision, accuracy and ruggedness. Than the modified method was used to estimate the percentage content of clotrimazole (1\%) in the finish product of Dabur international and verified this method by analyzing different pharmaceutical creams containing clotrimazole (1\%) as mentioned in Table 1.

\section{System suitability}

It is dependent on, the objective of the analytical procedure, its robustness and the availability of reference substances. The assessment for the suitability of the system was done using six (6) drug replicas at concentration of $500 \mu \mathrm{g} / \mathrm{mL}$. It was used to confirm that the resolution and reproducibility of the chromatographic system is adequate for the analysis to be done. The method was evaluated by analyzing the repeatability, retention time, peak area, tailing factor, theoretical plates (Tangent) of the column with relative standard deviation and base line correction (ICH Q2B, 1996) [7].

Specificity: of the method demonstrates that there is no interference between the pharmacologically active ingredients from excipients that incorporated in their dosage forms (ICH Q2B, 1996).

Linearity: refers to a proportional relationship between the drug concentration and the instrument response (or signal) used to measure the drug (ICH Q2B, 1996). The linearity for the present method was determined by analyzing standard solution of clotrimazole in the concentration range of $0.01-0.07 \%(100-700 \mu \mathrm{g} / \mathrm{mL})$. To evaluate the LOD and LOQ of the method, serial dilutions were made from the stock solution in the range of $0.25-10 \mu \mathrm{g} / \mathrm{mL}$.

Accuracy: refers to the difference between the average assay values and the true (known) drug concentrations (ICH Q2B, 1996). To validate the accuracy and recovery of the method from herbal health care cream, samples were prepared by known amount of drug at three different concentration levels (in duplicate) i.e., $80 \%, 100 \%$ and $120 \%$ of the label claim and were analyzed according to the procedures.

Precision: relates to the variation or reproducibility of the data. Precision measurements should be obtained by replication of various drug concentrations and by the replication of standard concentration curves prepared separately on different days (ICH Q2B, 1996). The method precision was analyzed under the quality of repeatability that had been done by six (6) determinations at $100 \%$ of the test concentration, intermediate precision (intra-day and inter-day variation), and reproducibility (an inter-laboratory trial).

Robustness: studies were done on method precision using a sample concentration of $250 \mu \mathrm{g} / \mathrm{mL}$ by making slight variations in flow rate and concentration of methanol: $\mathrm{K}_{2} \mathrm{HPO}_{4}$ solution in the mobile phase.

For content assay of cream: $2.5 \mathrm{~g}$ were accurately weighed and transferred carefully to a $100 \mathrm{~mL}$ volumetric flask. The cream was dissolved in methanol and shaken for about 15 minutes. The solution was filtered through $0.22 \mu \mathrm{m}$ Millipore filter paper. The filtered sample solution was then injected. The final concentration of working solution was equivalent to $0.25 \mathrm{mg} / \mathrm{mL}$.

\section{Results and Discussion}

Clotrimazole prevents the growth of fungi by interfering with the production of the membrane that surrounds fungal cells. It is commonly available without a prescription in various dosage forms, such as a cream, vaginal tablet, or as a prescription troche or throat lozenge. In the present study a health care cream was prepared and a HPLC analytical method was modified for the estimation of clotrimazole in health care products. It is a simple, sensitive, and an easy HPLC method 
Citation: Usman S, Zulfiqar AM, Shah J, Ramesh V, Sudhir S (2017) Modification and Validation of HPLC Analytical Method for Estimation of Clotrimazole in Health Care Products. Nat Prod Chem Res 5: 247. doi: 10.4172/2459-6836.1000247

Page 3 of 7

\begin{tabular}{|c|c|c|c|}
\hline Brand Name & Dabur Anti-itch Cream & Cream -A & Cream -B \\
\hline Origin & UAE & USA & Oman \\
\hline Strength of Clotrimazole & $1.0 \%$ & $1.0 \%$ & $1.0 \%$ \\
\hline Batch No & - & 5 SNNA25003 & 5 ES8015A \\
\hline Mfg Date & - & $03-2015$ & $1.0 \%$ \\
\hline Exp Date & - & $02-2018$ & $12-2015$ \\
\hline
\end{tabular}

Table 1: Label information of different pharmaceutical products containing clotrimazole.

to operate, using UV detection for the determination of clotrimazole not only as raw material as well in the herbal health care products. The method is selective and reproducible, capable to separate all possible excipients and help to quantify accurately the amount of clotrimazole in health care product (Figure 3).

One of the most important advantages of analytical method validation is reduction of pharmaceutical cost and increase the confidence of developer as well as the user. Similarly it plays a supreme importance during the process of drug discovery, release to market and development, culminating in a marketing approval.

System suitability was conducted by injecting six (6) replicated injection of freshly prepared clotrimazole RS solution at concentration of $500 \mu \mathrm{g} / \mathrm{mL}$. The percentage coefficient variation (\% CV) of the retention times and the peak areas of clotrimazole were $0.504 \%$ and $1.453 \%$, respectively. The theoretical plate count, based on USP tangent calculations [9] for clotrimazole was $3656.63 \pm 29.66$ (Table 2). The average tailing factor for six consecutive peaks was 1.036 , factor equal to or near to 1.0 is signified as complete symmetrical (Table 2).

The linearity of the peak area response was determined by making a seven concentration points in the range of $0.01-0.07 \%$. Calibration curve was plotted against peak area verses concentration. The linearity was evaluated by linear regression analysis using least square method. The linear regression coefficient was $\mathrm{r}^{2}=0.9996$ (Figure 4).

The calculations for Limit of detection (LOD) and limit of quantification (LOQ) were done on the basis of peak responses of clotrimazole standard solution. LOD is determined by the signal to noise ratio and generally acceptable detection limit ratio is 3:1 and it was found $0.25 \mu \mathrm{g} / \mathrm{mL}$. LOQ is determined by the signal to noise ratio and a typical signal to noise ratio is $10: 1$ which is acceptable for estimating the quantification limit. It was found to be $0.5 \mu \mathrm{g} / \mathrm{mL}$ for clotrimazole (Table 3).

Accuracy of the method was determined by preparing samples of anti-itching cream in duplicate at the three concentration levels over a range of $80-120 \%$ and assayed according to the procedure. The recoveries at three concentrations were found within the range of 101.2 to $103.8 \%$ of the label claim of clotrimazole and \%CV values for each level ranged from 0.01 to $0.59 \%$ as per ICH guidelines (Table 4).

The precision of the method was evaluated for repeatability (Instrumental precision) and intermediate precision. Instrumental precision expresses the precision under the same operating conditions over a short interval of time. It is also termed intra-assay precision [10]. Six samples were prepared at the $100 \%$ level and assayed according to the procedure described. The results of the precision study are summarized in Table 5 . The mean percent recovery of clotrimazole was $103.5 \%$ of the label claim with \%CV of $0.612 \%$. Intermediate precision of the method was demonstrated by different analyst on different day, using different HPLC column and system. For intermediate precision, the percentage relative standard deviation of clotrimazole was found to be 0.35 to $1.43 \%$. These values were well within the acceptable limit of $\leq 2 \%$ as per USP (Table 6 ).

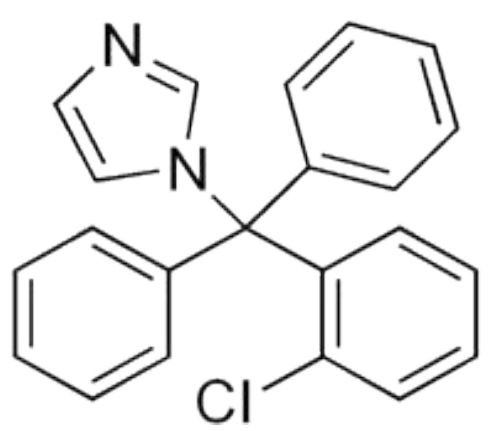

Figure 2: Primary structure of clotrimazole.

The robustness of a method is its ability to remain unaffected by small changes. Robustness study was performed on method precision sample by making slight variations in flow rate, amount of methanol and buffer and changes in $\mathrm{pH}$ one at a time. The results of robustness in the present method showed no major changes occurring over changes in flow rate from $1.4 \mathrm{~mL} / \mathrm{min}$. to $1.6 \mathrm{~mL} / \mathrm{min}$, showing a recovery of approximately $100 \%$. In case of variation in the amount of methanol $80-85 \%$ and $\mathrm{K}_{2} \mathrm{HPO}_{4}$ buffer $15-20 \%$, there was no significant changes in recovery percentage.

After modification and validation, the method applied for the analysis of clotrimazole in formulated herbal cream as well it was used to analyze different pharmaceutical creams that contain clotrimazole, available in local market of Ras Al Khaimah (Table 1). The developed method is so simple, easy and applicable. It could be easily used for the analysis of compound in its dosage form. Retention time is between 6-7 minutes that could also be adjusted according the needs.

Table 7 represents the results of the assay of clotrimazole cream. The active contents recovery of the three (3) brands was between 98.43$100.16 \%$, indicating that in spite of the difference in the excipients used by manufacturers, the recovery of active drug was possible by developed method as per BP/USP specifications indicating its good selectivity. The drug content in the health care cream (1\%) was estimated, were similar to the labeled claim of marketed formulations. The standard and sample chromatograms of Dabur Antiitch, Cream-A, Cream-B and Cream-C were shown in Figure 5, indicating that the proposed method is also suitable for the separation of Betamethasone from combined dosage form (Figures $5 \mathrm{c}$ and $5 \mathrm{~d}$ ).

The good thing of this method is that the preparation of standard and sample solution is very simple and easy just in the methanol; the mobile phase is consisted on methanol and phosphate buffer, capable to separate the clotrimazole from herbal cream by using simple C18 column. Whereas different HPLC analytical method for estimation of clotrimazole from cream are available in literature but they have complicated method of sample and standard preparation [11], estimation is done for lozenges dosage form by Gracemart C18 column [12], separation is done by using Kromasil C18 with maintaining $40^{\circ} \mathrm{C}$ temperature [13]. 
Citation: Usman S, Zulfiqar AM, Shah J, Ramesh V, Sudhir S (2017) Modification and Validation of HPLC Analytical Method for Estimation of Clotrimazole in Health Care Products. Nat Prod Chem Res 5: 247. doi: 10.4172/2459-6836.1000247
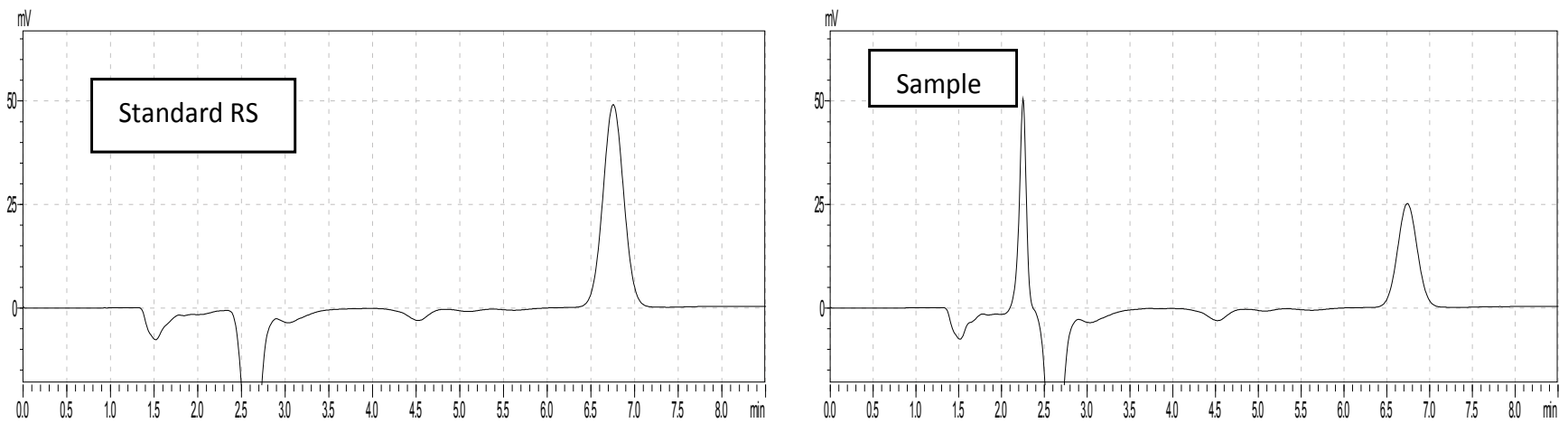

Figure 3: a) $510 \mu \mathrm{g} / \mathrm{ml}$ clotrimazole RS in methanol, b) $251 \mu \mathrm{g} / \mathrm{ml}$ concentration of clotrimazole from herbal health care product.

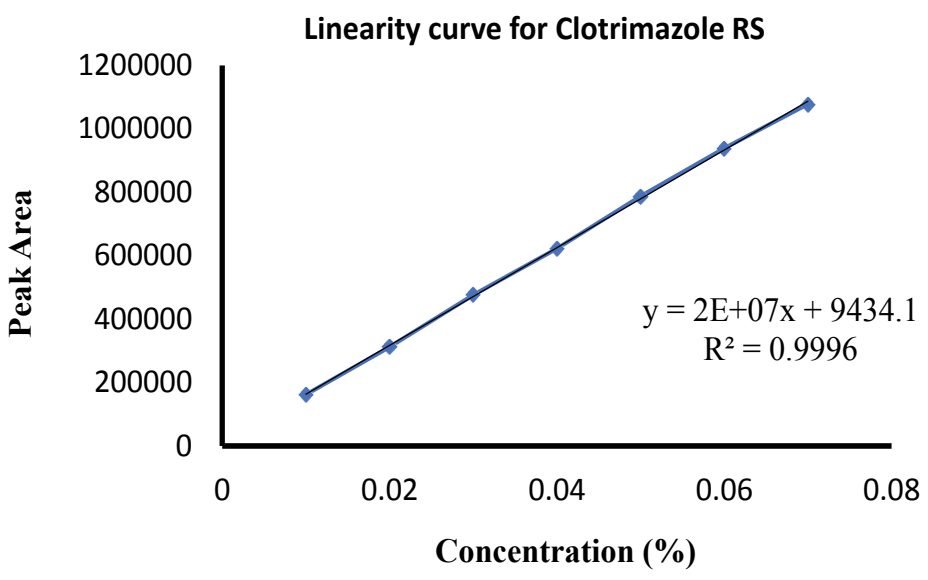

Figure 4: Calibration curve shows linearity over the concentration range.

\begin{tabular}{|c|c|c|c|c|}
\hline Injection number & Retention time (min) & $\begin{array}{c}\text { Peak area of } \\
\text { Clotrimazole }\end{array}$ & $\begin{array}{c}\text { Tailing factor } \\
\text { Plate count }\end{array}$ & $\begin{array}{c}\text { Base line Correction } \\
\text { As per MP }\end{array}$ \\
\hline 1 & 6.754 & 827606 & 1.035 & 3642.78 \\
\hline 2 & 6.792 & 855512 & 1.037 & 3683.11 \\
\hline 3 & 6.756 & 820504 & 1.036 & 3703.77 \\
\hline 4 & 6.725 & 831857 & 1.034 & 3629.46 \\
\hline 5 & 6.702 & 840827 & 1.036 & 3637.73 \\
\hline 6 & 6.709 & 838495 & 1.035 & 3642.93 \\
\hline Mean & $\mathbf{6 . 7 3 9 6 6 7}$ & $\mathbf{8 3 5 8 0 0 . 2}$ & $\mathbf{1 . 0 3 6}$ & \\
\hline SD & $\mathbf{0 . 0 3 4 0 1 6}$ & $\mathbf{1 2 1 4 7 . 0 4}$ & \\
& & \\
\end{tabular}

Table 2: System Suitability parameters for Clotrimazole.

\begin{tabular}{|c|c|c|}
\hline Standard number & Concentration $\mu \mathrm{g} / \mathrm{mL}$ & Peak Area \\
\hline 1 & 10 & 19316 \\
\hline 2 & 5 & 8747 \\
\hline 3 & 2 & 3349 \\
\hline 4 & 1 & 1656 \\
\hline 5 & 0.5 & 855 \\
\hline Slope & \multicolumn{2}{|c|}{1944.4} \\
\hline Intercept & \multicolumn{2}{|c|}{409.53} \\
\hline $\mathbf{R}^{2}$ & \multicolumn{2}{|c|}{0.9978} \\
\hline LOD & \multicolumn{2}{|c|}{$0.25 \mu \mathrm{g} / \mathrm{mL}$} \\
\hline LOQ & \multicolumn{2}{|c|}{$0.5 \mu \mathrm{g} / \mathrm{mL}$} \\
\hline
\end{tabular}

Table 3: Estimation of LOD and LOQ. 
Citation: Usman S, Zulfiqar AM, Shah J, Ramesh V, Sudhir S (2017) Modification and Validation of HPLC Analytical Method for Estimation of Clotrimazole in Health Care Products. Nat Prod Chem Res 5: 247. doi: 10.4172/2459-6836.1000247
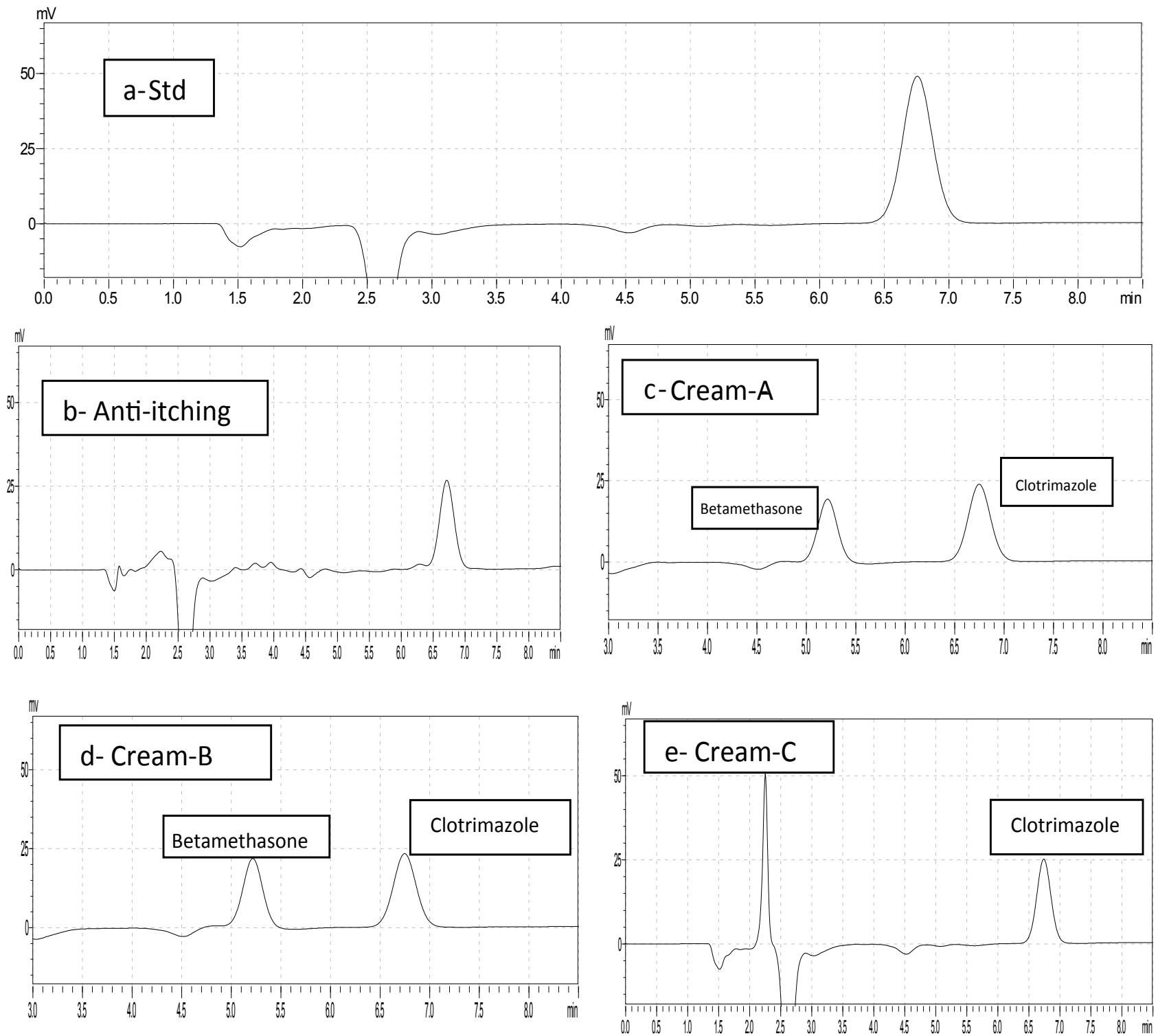

Figure 5: a) Standard clotrimazole RS in methanol; b) Separation of clotrimazole from herbal health care product; c) Separation of clotrimazole from Cream-A; d) Separation of clotrimazole from Cream-B; e) Separation of clotrimazole from Cream-C.

\begin{tabular}{|c|c|c|c|c|c|c|c|}
\hline \multicolumn{8}{|c|}{$80 \%$ Level } \\
\hline Assay & $\begin{array}{c}\text { Sample Amount } \\
\text { (gram) }\end{array}$ & Run-I & Run-II & Mean & $\%$ Recovered & $\% \mathrm{CV}$ & $\%$ of LC \\
\hline Sample-1 & 2.05 & 318449 & 319853 & 319151 & 79.6 & \multirow{2}{*}{0.01} & 102.3 \\
\hline Sample- 2 & 2.07 & 327063 & 320779 & 323921 & 80.74 & & 103.8 \\
\hline \multicolumn{8}{|c|}{$100 \%$ Level } \\
\hline Sample-1 & 2.51 & 395243 & 407836 & 401540 & 100.09 & \multirow{2}{*}{0.1128} & 103.0 \\
\hline Sample- 2 & 2.49 & 402273 & 402117 & 402195 & 100.25 & & 103.1 \\
\hline \multicolumn{8}{|c|}{$120 \%$ Level } \\
\hline Sample-1 & 3.01 & 486943 & 485721 & 486332 & 121.23 & \multirow{2}{*}{0.59} & 102.1 \\
\hline Sample- 2 & 3.09 & 484449 & 479986 & 482218 & 120.22 & & 101.2 \\
\hline
\end{tabular}

Table 4: Accuracy data for the assay of clotrimazole cream. 
Citation: Usman S, Zulfiqar AM, Shah J, Ramesh V, Sudhir S (2017) Modification and Validation of HPLC Analytical Method for Estimation of Clotrimazole in Health Care Products. Nat Prod Chem Res 5: 247. doi: 10.4172/2459-6836.1000247

Page 6 of 7

\begin{tabular}{|c|c|c|c|c|}
\hline \multirow[b]{2}{*}{ Sample Number } & \multirow[b]{2}{*}{ Sample Amount (gram) } & \multicolumn{2}{|c|}{ Clotrimazole } & \multirow[b]{2}{*}{$\%$ Recovery } \\
\hline & & $\begin{array}{l}\text { Theoretical } \\
\text { peak area }\end{array}$ & $\begin{array}{l}\text { Measured } \\
\text { peak area }\end{array}$ & \\
\hline 1 & 2.494 & \multirow{6}{*}{389982} & 406239 & 104.2 \\
\hline 2 & 2.485 & & 404743 & 103.8 \\
\hline 3 & 2.485 & & 405031 & 103.9 \\
\hline 4 & 2.483 & & 404192 & 103.6 \\
\hline 5 & 2.467 & & 401772 & 103.0 \\
\hline 6 & 2.510 & & 399877 & 102.5 \\
\hline Mean & 2.487 & 389982 & 403643 & 103.5 \\
\hline SD & 0.0142 & & 2360.53 & 0.633 \\
\hline$\% \mathrm{CV}$ & 0.57 & & 0.585 & 0.612 \\
\hline
\end{tabular}

Table 5: Precision Repeatability Data.

\begin{tabular}{|c|c|c|c|c|c|}
\hline Conc. (\%) & $1^{\text {st }}$ day & $2^{\text {nd }}$ day & Mean & $\pm \mathrm{SD}$ & $\%$ RSD \\
\hline \multirow{2}{*}{0.01} & 163830 & 162180 & 163005 & 1166.73 & 0.72 \\
\hline & 164871 & 161582 & 163227 & 2325.68 & 1.43 \\
\hline Mean & 164351 & 161881 & 163116 & 1746.2 & 1.07 \\
\hline \multirow{2}{*}{0.02} & 317293 & 312634 & 314964 & 3294.41 & 1.05 \\
\hline & 311985 & 310449 & 311217 & 1086.12 & 0.35 \\
\hline Mean & 314639 & 311542 & 313091 & 2190.27 & 0.70 \\
\hline \multirow{2}{*}{0.03} & 484746 & 476301 & 480524 & 5971.52 & 1.24 \\
\hline & 486301 & 481249 & 483775 & 3572.31 & 0.74 \\
\hline Mean & 485524 & 478775 & 482150 & 4771.91 & 0.99 \\
\hline
\end{tabular}

Table 6: Intermediate Precision Data.

\begin{tabular}{|c|c|c|c|c|c|c|c|c|c|c|c|}
\hline & \multicolumn{3}{|c|}{ Standard Peak area } & \multicolumn{2}{|c|}{ Dabur Anti-itch Cream } & \multicolumn{2}{|c|}{ Cream-A } & \multicolumn{2}{|c|}{ Cream-B } & \multicolumn{2}{|c|}{ Cream-C } \\
\hline & Std 1 & Std 2 & Std 3 & Sp 1 & Sp 2 & Sp1 & Sp2 & Sp1 & Sp2 & Sp1 & Sp2 \\
\hline & 840827 & 831857 & 838495 & 407836 & 407171 & 384837 & 383654 & 380992 & 380440 & 405254 & 402117 \\
\hline Average Area & \multicolumn{3}{|c|}{837060} & \multicolumn{2}{|c|}{407504} & \multicolumn{2}{|c|}{384246} & \multicolumn{2}{|c|}{380716} & \multicolumn{2}{|c|}{403686} \\
\hline RSD & \multicolumn{3}{|c|}{0.56} & \multicolumn{2}{|c|}{0.12} & \multicolumn{2}{|c|}{0.22} & \multicolumn{2}{|c|}{0.1} & \multicolumn{2}{|c|}{0.55} \\
\hline Sp. Wt (gm) & \multicolumn{3}{|c|}{0.051} & \multicolumn{2}{|c|}{2.51} & \multicolumn{2}{|c|}{2.369} & \multicolumn{2}{|c|}{2.357} & \multicolumn{2}{|c|}{2.456} \\
\hline \multicolumn{4}{|c|}{ \%age Purity } & \multicolumn{2}{|c|}{0.9892} & \multicolumn{2}{|c|}{0.9883} & \multicolumn{2}{|c|}{0.9843} & \multicolumn{2}{|c|}{1.0016} \\
\hline \multicolumn{4}{|c|}{ Tolerance Limit as per BP/USP } & \multicolumn{8}{|c|}{$95.00-105.00 \%$ of the labeled amount of Clotrimazole } \\
\hline & & & & & & & & & & & $6 \%$ \\
\hline \multicolumn{4}{|c|}{ Label Claim } & \multicolumn{8}{|c|}{$1.00 \%$} \\
\hline
\end{tabular}

Table 7: Compression of content assays of Clotrimazole cream with marketed cream.

\section{Conclusion}

A HPLC method for determination of Clotrimazole in cream was modified and validated as per ICH and FDA guidelines. Linearity, accuracy, precision, and robustness results reveal that the proposed method is accurate, precise, rapid and simple. The sample preparation is simple, and the elution is isocratic. The method is amenable to the analysis of large number of samples with excellent precision and accuracy. Statistical analysis proves that method is repeatable, sensitive and selective for the analysis of Clotrimazole in herbal health care cream as well in pharmaceutical formulation. Based on this evidence the method can be stated as highly economical and it is recommended for routine use in quality control studies.

\section{Acknowledgements}

The authors would like to thank the Dean, RAK college of Pharmaceutical Sciences and Vice Chancellor, RAK Medical and Health Sciences University, Ras al Khaimah, UAE for lab, equipment and chemical facilities to carry the work. We would also like to thanks Dabur International Ltd. for their moral and generous help in following up the research/project.

\section{References}

1. Behnam D (2016) USP29 clotrimazole. p: 2130 . Available from: http://www.pharmacopeia.cn/v29240/usp29nf24s0_m18880.html Accessed on: $27^{\text {th }}$ December 2016 .
2. Marieb H (2010) Human Anatomy and Physiology. Toronto: Pearson Jump up "LOTRIDERM". RxMed, p: 643.

3. Clotrimazole Official FDA Information (2011) Side effects and uses. FDA Retrieved: 28 December 2011.

4. United States Pharmacopeia (2014) United States Pharmacopeial Convention. 37th edn. Rockville.

5. US National Library of Medicine (2008) Drug label information. NDC Code 0065-0002-03. Alcon Laboratories, Inc., Available from: http://dailymed.nlm.nih.gov/dailymed/lookup.cfm?setid=4c9ae54a-97a0-4613a092-31e86d9bfc91 Accessed on: 27 th December 2016.

6. United States Pharmacopeia (2005) United States Pharmacopeial Convention 28th edn. Rockville.

7. Guidance for Industry (1996) Q2B Validation of analytical procedures methodology. pp: 1-10.

8. Center for Drug Evaluation and Research (1994) Reviewer guidance: validation of chromatographic methods. pp: 1-30.

9. United States Pharmacopeia (2004) XXV11. Chromatography.

10. Global Quality Guideline (2002) Validation of analytical procedures. Number: G-69, Version 1.0 .

11. Manassra A, Khamis M, el-Dakiky M, Abdel-Qader Z, Al-Rimawi F (2010) Simultaneous HPLC Analysis of Betamethasone and Clotrimazole in Cream Formulations. Pharm Anal Acta 1: 113. 
Citation: Usman S, Zulfiqar AM, Shah J, Ramesh V, Sudhir S (2017) Modification and Validation of HPLC Analytical Method for Estimation of Clotrimazole in Health Care Products. Nat Prod Chem Res 5: 247. doi: 10.4172/2459-6836.1000247

12. Prashanth K, Jagadish PC, Muddukrishna M, Krishnamurthy B (2014) Development and validation of stability indicating HPLC method for Clotrimazole lozenges formulation. International Journal of Pharmacy and Pharmaceutical Sciences 6: 126-129.
13. Dhudashia KR, Patel AV, Patel CN (2013) Development and validation of reversed-phase HPLC method for simultaneous estimation of clotrimazole and beclomethasone dipropionate in lotion and cream dosage form. Chron Young Sci 4: 102-107. 